\title{
How Unreligious are the Religious "Nones"? Religious Dynamics of the UNAFFILIATED IN CANADA
}

\author{
SARAH WiLKInS-LAFLAMME
}

\begin{abstract}
Increasing rates of religious non-affiliation have been a fundamental transformation of Canadian society since the 1970s. Such increases, present across the West, have received much attention from researchers and sparked much debate. Two competing frameworks identify differing mechanisms behind the rise in individuals declaring having no religion. Secularization theories see this trend as indicating a decline of all things religious. By contrast, individualization theories argue it is only institutional indicators of religiosity which are on the decline, and individually constructed spirituality systems are becoming the norm. Yet, little systematic empirical testing has been done on this subject, especially in the Canadian context. Generating single- and multi-level regression models with data from the Canadian GSS and the ISSP, this paper undertakes a novel comparison of religiosity levels among the unaffiliated between Canadian provinces, between a number of Western nations and regions as well as between age groups.
\end{abstract}

Keywords: Religion; Canada; religious nones; unaffiliated; secularity; secularization

Résumé. Depuis les années 1970, le Canada a connu une augmentation continue de la désaffiliation religieuse. Un tel accroissement, caractéristique des sociétés occidentales, a retenu l'attention de nombreux chercheurs et a entamé plusieurs débats. Deux cadres théoriques expliquent de manières distinctes la hausse des individus qui déclarent ne pas avoir de religion. Les théories de la sécularisation la perçoivent comme un indice de déclin de toute chose religieux. Les théories de l'individualisation quant à elles avancent que seuls les indicateurs institutionnels de la religiosité sont en déclin et les systèmes individuels de spiritualité deviennent la norme. Toutefois, peu d'études empiriques ont été effectuées de façon systématique à cet égard, notamment dans le contexte canadien. En employant divers techniques statistiques avec des données récentes des ESG et de l'ISSP, nous comparons la religiosité des « sans religion » parmi les provinces canadiennes, parmi divers pays occidentaux ainsi que parmi divers groupes d'âge.

Mots clés:: religion; Canada; sans religion; désaffiliation; sécularisation 


\section{INTRODUCTION}

The mutating role of religion in public and private life is one of the principal societal changes Canada has experienced since the end of the Second World War. The Quiet Revolution in Quebec in the 1960s which severely weakened a once influential Catholic Church (Lemieux 1990; Meunier and Wilkins-Laflamme 2011), the rapid shrinking of the mainline Protestant Churches in English-speaking Canada (Bibby 2011; Bowen 2004), and the pluralization in certain parts of the country of a once strongly Christian landscape (Beyer 2006; Bramadat and Seljak 2005) are but a few examples of the religious transformations still affecting Canadian society.

Some consider these transformations, found in similar forms throughout the Western world, as various facets of a more general process of secularization. This process would eventually lead to the disappearance of all forms of religion and religiosity from Europe and North America (Aarts et al. 2008; Bruce 2011; Voas and Crockett 2005). Growing rates of religious nones, i.e. individuals declaring having no religion when asked in surveys, are often the main indicator used to support these theories of religious decline. For example, in Canada between 1985 and 2010 the rate of individuals declaring no religion in the Canadian General Social Surveys went from $10.5 \%$ to $23.8 \%$, an increase of $126.7 \%$ over 25 years. Yet, few in the country have studied the religious none in more detail. The focus has stayed for the most part on the remaining religious individuals, their levels of religiosity, their demographic characteristics and their social attitudes and behaviours.

This being said, evidence is building outside of Canada that the unaffiliated are not as unreligious as many often assume. Rather than forming one homogenous secular group, individuals declaring having no religion are characterized by varying levels of religiosity (Baker 2012; Baker and Smith 2009a; Cimino and Smith 2011; Hout and Fisher 2002; Lim, MacGregor and Putnam 2010; Storm 2009; Zuckerman 2009). This is an important development not only for the study of religion, but also for other social phenomena which religiosity is known to impact, such as physical and mental health (Koenig, King and Carson 2012), choice of educational track (Loury 2004; Mayrl and Oeur 2009), volunteering (Bowen 2004; Lim and MacGregor 2012), family formation (Eggebeen and Dew 2009; Village, Williams and Francis 2010) and vote choice (Ang and Petrocik 2012; Evans and de Graaf 2013). A rise in non-affiliation may not be coupled with a complete decline of other types of religiosity. What then of the Canadian religious nones? Are the unaffiliated completely removed from all forms of religion, or do some remain 
spiritual seekers without a church or religious group to call home? Are religious patterns among the unaffiliated, or lack thereof, similar across Canadian provinces and across age groups? How do Canadian regions compare with other Western nations in this regard? The goal of this paper is to address these questions by exploring some of the religious characteristics of the unaffiliated using recent social survey data from both Canada and other Western nations.

\section{Theoretical Considerations}

The most popular framework in the field of sociology of religion which accounts for the existence and growing numbers of unaffiliated individuals in Western societies is stages of decline theory. This theoretical model is inspired by the classic secularization argument that modern social transformations, such as rationalization, individualization and improved material conditions, have led and will continue to lead to the general decline of religious institutions and personal religiosity. Among researchers showing evidence of this decline, there is a growing consensus that secularization happens in stages: in a society with initially high rates of religious individuals, over time and across generations these actively religious would become less involved with religious groups, then completely detached from institutional religion (not affiliated to any religious group), and then completely removed from all forms of religiosity and spirituality (Bruce 2011; Dobbelaere 2002; Voas 2009). Consequently, the end product of this secularization process would be a large majority of individuals unaffiliated and completely unreligious. To support this framework, researchers point not only to the almost universal declines in church attendance and affiliation in Europe, but also to more recent declines in basic religious beliefs (Aarts et al. 2008; Voas and Crockett 2005).

However, this stages of decline framework is still criticized. Some researchers emphasize that only institutional religion is on the decline, with a persistence of more personal forms of religiosity (Bowen 2004; Campiche 2010; Davie 2000; Hervieu-Léger 2003; Hout and Fisher 2002). According to this individualization framework, in the modern era individuals move progressively away from churches and religious groups for a variety of reasons, including a dislike of the political involvement and undertones as well as the authoritarianism found in many Churches, a disagreement with the Church's stance on certain social issues (homosexuality, pre-marital sex, abortion, etc.) or simply a lack of time and/ or will to participate. Nevertheless, either due to a remaining religious 
socialization, a need to answer life's big questions, or both, a majority of individuals would retain more personal indicators of religiosity, such as spiritual beliefs and personal prayer and meditation.

There is some empirical evidence in the US and Europe supporting the fact that unaffiliated individuals do not form one homogenous secular group. Rather, they can be classified into different categories according to their levels of personal religiosity and anti-religious sentiment: believing without belonging (or unchurched believers), liminal nones (change from being unaffiliated to affiliated and back again), as well as active or ordinary atheists and agnostics (Altemeyer 2009; Baker and Smith 2009a; Hout and Fisher 2002; Lim, MacGregor and Putnam 2010; Storm 2009). Yet, with few cross-temporal and cross-generational comparisons, it is impossible to say whether this evidence supports the stages of decline or individualization frameworks. A great deal of regional variation is also likely in the presence and size of these different types of unaffiliated individuals, since declaring no religion can have different meanings in different contexts. For example, being unaffiliated in Northern Ireland still has strong political connotations (Mitchell 2004), whereas for many Nordic and Catholic countries it refers more to distancing oneself from a specific institution which still has strong ties to the State (Demerath 2000). In the US, being unaffiliated may be considered more a matter of consumer choice in a religious market, or a reaction to the Religious Right (Hout and Fisher 2002; Stark and Finke 2000).

What then of Canada? With his Project Canada surveys, Bibby (2002; 2011) has shown evidence that, in $2000,40 \%$ of unaffiliated individuals in the country believed in God, and in $200535 \%$ believed in some form of life after death. In 2000, 19\% said they had experienced God's presence, and $13 \%$ said they prayed weekly. However, in-depth analyses of the unaffiliated in Canada remain rare in the field of sociology. Most surveys contain only a couple of religious variables, not treating religion and religiosity as multidimensional concepts. In surveys which do contain multiple religiosity indicators, unaffiliated sample sizes tend to be too small to be able to produce any meaningful results. More generally, the focus of studies in the field has most often remained on the actively or nominally religious, rather than on the unaffiliated. Additionally, in the Canadian context the size of the unaffiliated group varies to a great extent between provinces and regions (Bowen 2004; Eagle 2011; Wilkins-Laflamme 2014). Consequently, levels of religiosity among the unaffiliated are likely to vary in a similar fashion, something which has also not been addressed in previous studies. 


\section{Research Questions, Hypotheses and Methods}

Questions thus still remain surrounding the behaviour of the religious nones in the country. To what extent are the unaffiliated unreligious in Canada? How does this vary across Canadian provinces? How do religiosity levels of the Canadian unaffiliated compare with those in other Western nations and regions? To what extent have the levels of religiosity of the unaffiliated changed across birth cohorts in Canadian regions? The stages of decline framework provides direction in attempting to answer these questions, and so we can put forward the following hypotheses:

$Q_{1}$ : To what extent do levels of religiosity among the unaffiliated vary between Canadian provinces?

$\mathrm{H}_{1}$ : In areas with larger unaffiliated groups, or in a more advanced stage of secularization, levels of religiosity will be lower among these unaffiliated compared with their counterparts elsewhere.

$\mathrm{Q}_{2}$ : To what extent do differences between the unaffiliated and affiliated in levels of annual religious service attendance vary between Western nations and regions?

$\mathrm{H}_{2}$ : In areas with larger unaffiliated groups, or in a more advanced stage of secularization, these differences will be greater.

$\mathrm{Q}_{3}$ : To what extent do levels of religiosity change across birth cohorts among the unaffiliated in Canada?

$\mathrm{H}_{3}$ : Levels of religiosity among the unaffiliated will be lower for younger birth cohorts exposed to less religious socialization and living in a more secular social environment.

\section{DATA}

To test these hypotheses, we used data from the 2008-2010 Canadian General Social Surveys (GSS) and from the 2008-2010 International Social Survey Programme (ISSP) (ISSP Research Group 2012; Statistics Canada 2012). Regarding the GSSs, cycles 22-24 (2008-2010) contain a national randomized sample of approximately 15,400 to 20,400 respondents per year of 15 years of age or older from all 10 provinces (excluding institutional residents and individuals living in the territories). The combined dataset contains a total of just over 55,200 respondents (11,341 unaffiliated) for the three-year period. The use of three cycles was preferred here to increase sample size while keeping period effects to a minimum. 
For the international comparison, 2008-2010 ISSP data was pooled with the 2010 GSS sample. Every year since 1984, the ISSP Research Group publishes a combined dataset of variables from a number of countries across the world (country samples ranging from approximately 700 to 4000 respondents), with special thematic modules running annually. Using three waves from the ISSP allowed us to compare the Canadian provinces with a larger number of Western countries, since some countries were not included in one or two of the 2008-2010 waves. ${ }^{1}$ In order to keep Canadian regional variation in the international comparison, the 2010 GSS sample was pooled with the ISSP data, rather than using the existing Canadian data in the ISSPs. The pooled dataset contains a total of just over 55,200 respondents (12,549 unaffiliated) aged 15 years or older from 40 different countries and regions. ${ }^{2}$ These countries and regions were included for their comparable Western (or Westernized) and historically Christian contexts.

\section{VARIABLES}

For the Canadian analyses, GSS cycles 22-24 each contain multiple religiosity indicators, including religious affiliation, religious service attendance (which, since the mid 2000s, has also been asked of unaffiliated respondents), the frequency of personal religious practice and the importance of religious or spiritual beliefs in how the respondent lives her/his life. The initial dependent variables took the form of separate dichotomous variables in which respondents scored one if they:

- attended religious services at least once a month in the past year (excluding attendance for special events such as marriages, baptisms and funerals),

- attended religious services at least once in the last year (excluding attendance for special events such as marriages, baptisms and funerals),

1. If a country was included in the 2010 ISSP wave, this sample was selected. If not, either the 2009 or 2008 samples were selected (2009 before 2008).

2. These countries and regions include Alberta, Australia, Austria, British Columbia, Bulgaria, Croatia, Czech Republic, Denmark, Estonia, Finland, Flanders, France, Germany (East), Germany (West), Great Britain, Hungary, Iceland, Italy, Latvia, Manitoba, the Netherlands, New Brunswick, Newfoundland \& Labrador, New Zealand, Norway, Nova Scotia, Ontario, Poland, Portugal, Prince Edward Island, Quebec, the Republic of Ireland, Russia, Saskatchewan, Slovenia, Spain, Sweden, Switzerland, Ukraine and the USA. 
- prayed, meditated or practiced other forms of religiosity on their own at least once a week in the past year, and

- declared religious and/or spiritual beliefs as important or very important in how they live their lives.

We then combined the original (standardized) ordinal variables of religious service attendance, importance of beliefs and personal religious practice into a single religiosity scale by means of a principal components factor analysis to form one comprehensive dependent variable for overall level of religiosity. We also combined the two ordinal variables of importance of beliefs and personal religious practice into a second scale of only personal religiosity, once again by means of a principal components factor analysis. ${ }^{3}$

Our main independent variable was a dichotomous one for non-affiliation, the respondents scoring one if they declared having no religion. Figure 1 contains the proportion of unaffiliated individuals in each province in 2008-2010. ${ }^{4}$ In many of our statistical models, we also included the following socio-demographic controls, to better tease out differences in levels of religiosity due to the effect of non-affiliation: age group (five years), gender, marital status, first and second generation immigration, visible minority and aboriginal statuses, French as mother tongue (English in Quebec), level of education and year of study. ${ }^{5}$

3. For details regarding these scales and the results of the factor analyses, see Tables A.1 and A.2 in the online supplementary material.

4. It is also important to note at this stage that members of certain social groups are more likely to be unaffiliated than others (Baker 2012; Baker and Smith 2009b; Hayes 2000; Zuckerman 2009): these often include younger respondents, men, those who have never married, third generation white respondents and higher educated respondents. Table A.3 in the online supplementary material contains the results of five logistic regression models (one for each Canadian region) in which the outcome variable was declaring no religion, and various socio-demographic traits are included as independent variables to show their associations with non-affiliation in Canada.

5. See Tables A.4 and A.5 in the online supplementary material for descriptive statistics of all the variables included in the analyses. 
Figure 1: Proportion of Individuals Declaring No Religion, by Province, 2008-2010, Weighted

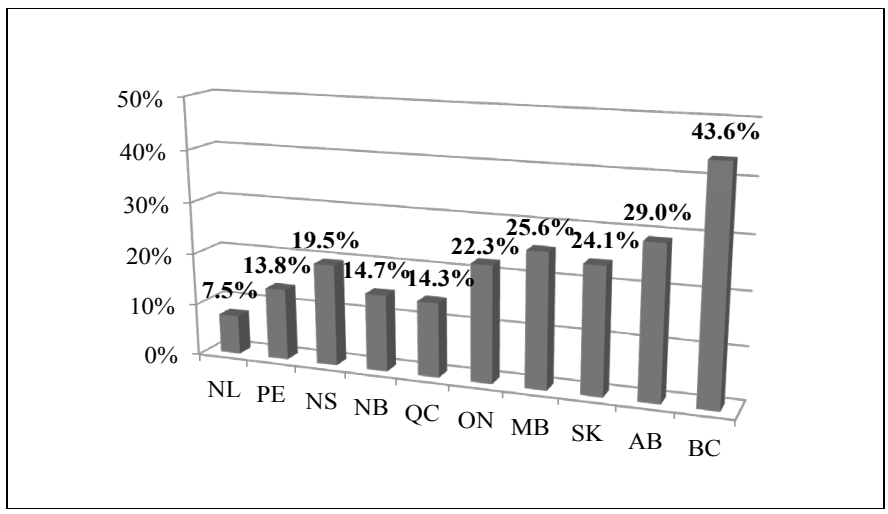

Between the GSS and ISSP data, only the indicators of affiliation and frequency of service attendance had an almost identical form. Consequently, for the international comparison the main dependent variable was yearly attendance (attended religious services at least once in the past year). ${ }^{6}$ Although this measure of institutional religiosity does not allow us to test the individualization framework as such, it does allow us to test the stages of decline theory across a large variety of national and regional contexts. We are also able to compare levels of religiosity of the unaffiliated in the Canadian provinces with those elsewhere. Our main independent variable for this cross-national comparison was once again a dichotomous variable for non-affiliation, and we added the following controls to our models: age, gender, marital status, year of study and a dummy for the attendance question specifically excluding special events (baptisms, marriages, funerals, etc.).

\section{Models}

With the Canadian data only, an initial series of binary logistic regression models were generated to measure and compare the difference in levels of religiosity between the unaffiliated and the affiliated for each of the four religiosity indicators and in each of the 10 Canadian provinces. Then, OLS regression models were run with the overall and personal religiosity scales to generate an overall comparison of the levels of religiosity among the unaffiliated between the 10 provinces. These OLS

6. This usually, but not always, refers to attending a religious service during a holiday period such as at Christmas or Easter. 
regression models also included age group dummies (five-year groups) to analyze how levels of religiosity among the unaffiliated have changed between cohorts. Both the logistic and OLS regression models included the socio-demographic controls.

For the international comparison, a series of two-level logistic randomcoefficient models were generated: one level of analysis for individuals and a second for countries/regions. At the individual level, a dichotomous variable for annual attendance was the outcome variable, and the fixed effects included non-affiliation as well as the socio-demographic controls. Being unaffiliated was also randomized, to see how the effect of non-affiliation on annual religious service attendance varies between countries and regions. The formal model can be written as follows:

YEARATT $_{i j}=\beta_{0}+\beta_{1}$ NOREL $_{i j}+\beta_{2}$ AGEGROUP $_{i j}+\beta_{3}$ LOGAGE $_{i j}+$ $\beta_{4}$ FEMALE $_{\mathrm{ij}}+\beta_{5}$ MARRIED $_{\mathrm{ij}}+\beta_{6}$ WIDOWED $_{\mathrm{ij}}+\beta_{7}$ SEPDIV $_{\mathrm{ij}}+\beta_{8} 2009_{\mathrm{j}}$ $+\beta_{9} 2010_{\mathrm{j}}+\beta_{10}$ EXCLUDERITES $_{\mathrm{j}}+u_{1 \mathrm{j}}$ NOREL $_{\mathrm{ij}}+u_{\mathrm{j}}+e_{\mathrm{ij}}$

where $i=$ individuals within country/region $j$

$j=$ countries/regions

\section{Results}

\section{Levels of Religiosity among the Unaffiliated in Canada}

Figure 2 contains the predicted probabilities for an average unaffiliated individual (black markers) and an average affiliated individual (grey markers) scoring one on each of the four religiosity indicators in each of the 10 provinces. These predicted probabilities were generated from eight separate logistic regression models with the unaffiliated and affiliated samples, each religiosity indicator as the main dependent variable, socio-demographic controls and province dummies.

The results in Figure 2 show that, somewhat unsurprisingly, in all provinces and for all four religiosity indicators the unaffiliated have lower probabilities than the affiliated. For example, an average unaffiliated Ontario resident has a probability of $2.8 \%$ of attending religious services at least once a month, whereas for an average affiliated Ontario resident the probability rises to $37.2 \%$. These rates of monthly church attendance among the unaffiliated are extremely low across Canada: the probabilities of an average unaffiliated individual attending at least once a month range only between 1\% in Quebec and 6.5\% in Newfoundland $\&$ Labrador. More surprisingly, unaffiliated individuals have by contrast non-negligible probabilities for the three other indicators, ranging from 
$15.8 \%$ in Quebec to $30.6 \%$ in New Brunswick for annual attendance, from $11.4 \%$ in Manitoba to $19 \%$ in PEI for weekly practice of personal religiosity, and from $30.2 \%$ in Quebec to $39.5 \%$ in Saskatchewan for beliefs being important.

As for differences between provinces, the unaffiliated in Quebec have the lowest predicted probabilities for scoring one on each of the four religiosity indicators, with the exception of weekly personal practice for which the unaffiliated in Manitoba score the lowest. This being said, most of the differences between provinces observed in Figure 2 are not statistically significant, each predicted probability falling for the most part within the others' $95 \%$ confidence intervals. The only significant differences between provinces are those between Quebec and all other provinces for monthly religious service attendance. The predicted probabilities are also significantly different between Quebec and Saskatchewan, Newfoundland \& Labrador and New Brunswick, as well as between British Columbia and New Brunswick for annual religious service attendance. This compared with the predicted probabilities of affiliated individuals, most of which are significantly different between provinces, especially for monthly attendance and weekly personal practice.

Figure 2: Predicted Probabilities of the Unaffiliated (Black Markers) and Affiliated (Grey Markers) Attending Religious Services at Least Once a Month and at Least Once a Year, as well as Practicing Personal Religiosity at Least Once a Week and Beliefs Being Important in Their Lives, 10 Canadian Provinces, 2008-2010, with CI (95\%)
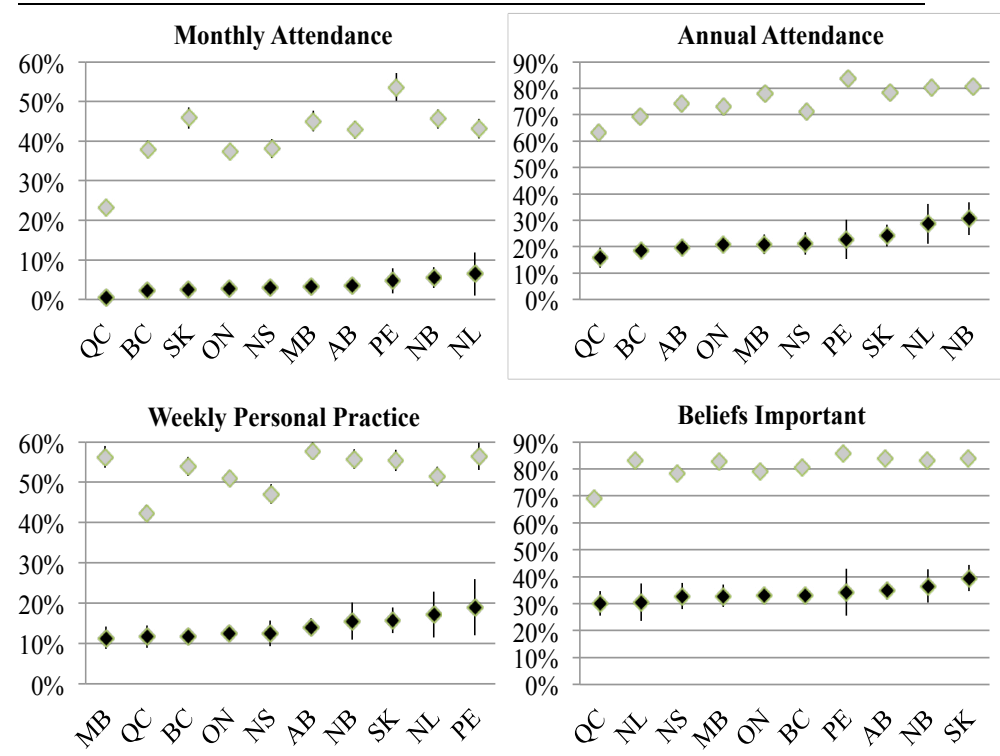
The results in Figure 2 also indicate that Quebec has some of the smallest differences between the unaffiliated and affiliated, meaning levels of the four indicators of religiosity there are low for the entire population. Unaffiliated BC residents also have relatively low predicted probabilities for most of the four religiosity indicators, but contrary to Quebec the differences between the unaffiliated and affiliated are much larger. ${ }^{7}$

By combining frequency of religious service attendance, frequency of personal religious practice and importance of beliefs into one scale of overall religiosity (lower scores = less religious) using a principal components factor analysis, we can summarize provincial differences in levels of religiosity among the unaffiliated. Figure 3 contains the predicted means of this scale among the unaffiliated for each of the 10 provinces. These predicted means were generated from OLS regression models controlling for socio-demographic traits. ${ }^{8}$

Figure 3: Predicted Mean Score of Overall Religiosity among the Unaffiliated, by Province, 20082010, with CI (95\%)

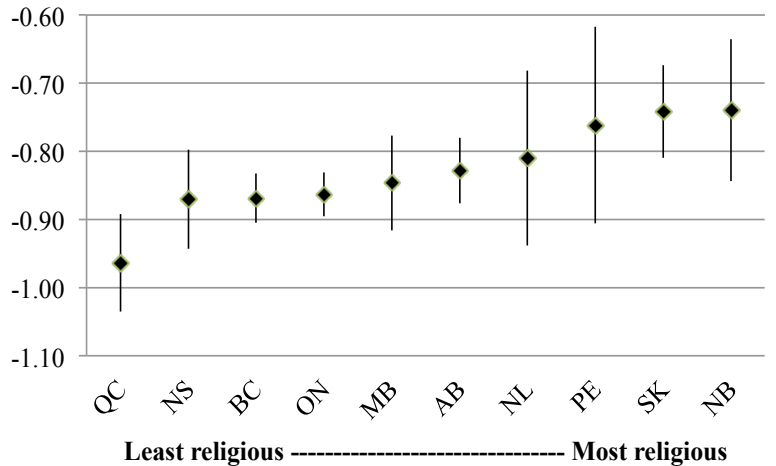

7. These differences between the unaffiliated and affiliated for the four religiosity indicators are shown in the form of coefficients for each province in Table A.6 in the online supplementary material. These coefficients (in odds ratios) were generated from a series of logistic regression models with the religiosity indicators as the outcome variables, declaring no religious affiliation as the main predictor variable and socio-demographic controls. These models were run separately for each province.

8. Similar results are also obtained if these OLS models are run with the personal religiosity scale (rather than the overall religiosity scale) as the outcome variable. See Figure A.1 in the online supplementary material. 
The predicted means in Figure 3 show once again that levels of religiosity among the unaffiliated in Quebec are especially low. In PEI, Saskatchewan and New Brunswick, these same levels are relatively high. Consequently, there are significant differences between some provinces in levels of religiosity among the unaffiliated, yet these differences do not necessarily accord with $\mathrm{H}_{1}$. In the Canadian context at least, those provinces with higher levels of non-affiliation are not necessarily characterized by the lowest levels of religiosity among their unaffiliated. Other contextual factors may be at play. In the Catholic-majority and Frenchspeaking context of Quebec for example, drastic religious decline occurred in tandem with the Quiet Revolution of the 1960s and issues of laïcité and State secularism are still highly contentious (Lemieux 1990; Milot 2002). It would seem then this particular historical and social context creates a specific religious landscape in the province: although a relatively large proportion of individuals still claim a religious affiliation (see Figure 1), religiosity levels are extremely low for those who are unaffiliated (see Figures 2 and 3). These low levels of religiosity also seem to be more of a province-wide trend, since the differences between the unaffiliated and affiliated in this regard are often smaller than those found elsewhere in the country (see Figure 2).

\section{Cross-National Comparison}

Let us see how the Canadian provinces compare with other Western nations and regions when it comes to levels of religiosity among the unaffiliated. Table 1 contains descriptive statistics, including the proportion of unaffiliated in each country and region at study, the proportion of annual religious service attendance among the general population, the proportion of the unaffiliated who attend religious services at least once a year, the sample size of each country/region and if their attendance question specifically excludes special events. Since we are restricted to frequency of attendance as our sole measure of religiosity for the international comparison, we focus here on annual attendance. It was also annual attendance which seemed to be present among a non-negligible portion of the unaffiliated in the Canadian provinces (as shown in Figure 2 ). Figure 4 then contains the adjusted coefficients from the multilevel model with annual attendance as the outcome variable and non-affiliation as the main predictor, included as a random coefficient at the country/ region level to see how the effect of non-affiliation on annual attendance varies between countries and regions. ${ }^{9}$ The fixed-effect coefficient for

9. For more results generated from this model, see Table A.7 in the online supplementary material. 
non-affiliation was adjusted with the variance from each country/region, showing how the magnitude of differences in annual attendance between the unaffiliated and affiliated varies across countries and regions. ${ }^{10}$

We can see from the proportions in Table 1 that the Atlantic Provinces and Quebec have relatively low levels of non-affiliation, falling into the lower half of countries and regions when ranked accordingly. By contrast, Ontario, the Prairie Provinces and British Columbia have relatively high levels of non-affiliation, falling into the upper half of countries/ regions. This being said, all the Canadian provinces have relatively high levels of annual religious service attendance among their unaffiliated, falling into the upper half when countries/regions are ranked according to this indicator. Regarding the stages of decline framework, the proportions in Table 1 do seem to indicate that countries and regions with larger unaffiliated groups also generally have lower levels of annual attendance among their unaffiliated. Yet, countries such as Croatia and Ireland who contain small proportions of unaffiliated individuals also have low levels of annual attendance among these respondents. ${ }^{11}$

Table 1: Descriptive Statistics by Country/Province, ISSPs 2008-2010 and GSS 2010

\begin{tabular}{lccccc}
\hline Country /province & $\begin{array}{c}\text { \% non- } \\
\text { affiliation }\end{array}$ & $\begin{array}{c}\text { \% annual } \\
\text { attendance } \\
\text { (general } \\
\text { population) }\end{array}$ & $\begin{array}{c}\text { \% annual } \\
\text { attendance } \\
\text { (unaffiliated } \\
\text { population) }\end{array}$ & Sample size & $\begin{array}{c}\text { Exclude } \\
\text { special } \\
\text { events in } \\
\text { attendance }\end{array}$ \\
\hline Canada & $21.6 \%$ & $59.0 \%$ & $20.2 \%$ & 15,390 & Yes \\
\hline Nwfld. \& Lab. & $8.5 \%$ & $68.6 \%$ & $21.8 \%$ & 957 & Yes \\
PEI & $12.9 \%$ & $72.9 \%$ & $24.2 \%$ & 489 & Yes \\
Nova Scotia & $20.0 \%$ & $59.4 \%$ & $23.9 \%$ & 963 & Yes \\
New Brunswick & $12.7 \%$ & $68.0 \%$ & $21.8 \%$ & 833 & Yes \\
Quebec & $14.4 \%$ & $53.1 \%$ & $17.5 \%$ & 2,277 & Yes \\
Ontario & $21.1 \%$ & $60.2 \%$ & $19.4 \%$ & 4,340 & Yes \\
Manitoba & $23.9 \%$ & $64.3 \%$ & $27.0 \%$ & 965 & Yes \\
Saskatchewan & $21.6 \%$ & $65.0 \%$ & $27.9 \%$ & 1,042 & Yes \\
Alberta & $26.7 \%$ & $58.0 \%$ & $19.8 \%$ & 1,311 & Yes \\
British Columbia & $38.0 \%$ & $47.0 \%$ & $16.8 \%$ & 2,213 & Yes \\
\hline
\end{tabular}

10. For the adjusted coefficients of the effect of non-affiliation on monthly attendance by country/region as well as other results generated from a multilevel model with monthly attendance as the outcome variable, see Figure A.2 and Table A.7 in the online supplementary material. The ranking of countries/ regions according to their effect of non-affiliation on monthly and annual religious service attendance is relatively similar, but the distinction of Protestant areas having smaller differences between the unaffiliated and affiliated is not as clear for monthly attendance.

11. When a multilevel model is run with only the unaffiliated sample, mean proportional size of the unaffiliated group in each country/region does not have a statistically significant effect on annual religious services attendance when other socio-demographic traits are controlled for. See Table A.8 in the online supplementary material for these results. 
Table 1 (Continued):

\begin{tabular}{|c|c|c|c|c|c|}
\hline Country/province & $\begin{array}{l}\text { \% non- } \\
\text { affiliation }\end{array}$ & $\begin{array}{c}\text { \% annual } \\
\text { attendance } \\
\text { (general } \\
\text { population) }\end{array}$ & $\begin{array}{c}\text { \% annual } \\
\text { attendance } \\
\text { (unaffiliated } \\
\text { population) }\end{array}$ & Sample size & $\begin{array}{c}\text { Exclude } \\
\text { special } \\
\text { events in } \\
\text { attendance }\end{array}$ \\
\hline Croatia & $4.1 \%$ & $76.6 \%$ & $6.5 \%$ & 1,210 & No \\
\hline Ireland & $7.0 \%$ & $74.4 \%$ & $9.4 \%$ & 2,049 & No \\
\hline Bulgaria & $7.7 \%$ & $85.2 \%$ & $21.5 \%$ & 1,003 & No \\
\hline Portugal & $8.0 \%$ & $59.4 \%$ & $23.9 \%$ & 1,000 & No \\
\hline Ukraine & $8.8 \%$ & $58.0 \%$ & $19.8 \%$ & 2,012 & No \\
\hline Iceland & $9.1 \%$ & $59.7 \%$ & $10.2 \%$ & 947 & No \\
\hline Italy & $10.2 \%$ & $70.0 \%$ & $24.6 \%$ & 1,078 & Yes \\
\hline Poland & $12.2 \%$ & $72.9 \%$ & $24.2 \%$ & 1,263 & No \\
\hline Spain & $13.5 \%$ & $60.2 \%$ & $19.4 \%$ & 1,215 & No \\
\hline Russia & $13.7 \%$ & $68.0 \%$ & $21.8 \%$ & 1,619 & No \\
\hline Denmark & $14.2 \%$ & $56.8 \%$ & $56.3 \%$ & 1,305 & No \\
\hline Hungary & $15.5 \%$ & $34.5 \%$ & $13.3 \%$ & 1,010 & No \\
\hline Austria & $16.3 \%$ & $67.5 \%$ & $71.4 \%$ & 1,019 & No \\
\hline Germany - West & $16.9 \%$ & $61.4 \%$ & $16.2 \%$ & 989 & No \\
\hline Finland & $18.6 \%$ & $41.3 \%$ & $13.3 \%$ & 1,211 & No \\
\hline USA & $18.6 \%$ & $47.0 \%$ & $16.8 \%$ & 1,430 & No \\
\hline Norway & $19.3 \%$ & $68.6 \%$ & $21.8 \%$ & 1,382 & Yes \\
\hline Switzerland & $21.5 \%$ & $65.0 \%$ & $27.9 \%$ & 2,441 & No \\
\hline Flanders & $25.7 \%$ & $88.2 \%$ & $46.3 \%$ & 1,142 & Yes \\
\hline Slovenia & $26.4 \%$ & $53.1 \%$ & $17.5 \%$ & 1,082 & No \\
\hline Latvia & $27.7 \%$ & $44.9 \%$ & $10.2 \%$ & 1,000 & Yes \\
\hline Sweden & $30.1 \%$ & $64.3 \%$ & $27.0 \%$ & 1,181 & No \\
\hline Australia & $33.4 \%$ & $39.8 \%$ & $4.5 \%$ & 1,525 & No \\
\hline New Zealand & $34.1 \%$ & $34.8 \%$ & $8.2 \%$ & 1,172 & No \\
\hline France & $39.1 \%$ & $72.0 \%$ & $15.2 \%$ & 2,817 & Yes \\
\hline Netherlands & $43.1 \%$ & $18.0 \%$ & $2.8 \%$ & 1,951 & No \\
\hline Great Britain & $52.3 \%$ & $40.2 \%$ & $4.2 \%$ & 928 & Yes \\
\hline Czech Republic & $64.8 \%$ & $55.3 \%$ & $9.0 \%$ & 1,428 & No \\
\hline Estonia & $65.7 \%$ & $42.0 \%$ & $6.7 \%$ & 1,005 & Yes \\
\hline Germany - East & $67.8 \%$ & $44.9 \%$ & $3.4 \%$ & 418 & No \\
\hline
\end{tabular}


The results in Figure 4 show that, in almost all countries and regions, there is a statistically significant positive association between affiliation and annual attendance: unaffiliated individuals are less likely to attend religious services at least once a year, compared with affiliated ones (negative coefficients). However, this is not the case in Iceland and the Netherlands ( $95 \%$ confidence intervals include 0$)$ when other sociodemographic traits are controlled for. The Canadian provinces have relatively smaller differences in annual attendance between their unaffiliated and affiliated, falling into the half of countries/regions with higher (but still negative) coefficients. Although the Canadian provinces have diverse proportions of unaffiliated, the provinces are similar to each other in the size of their differences in annual attendance between the unaffiliated and affiliated (all of them ranking closely to each other in Figure 4). Their coefficients are also similar in size to those of some of the Nordic countries, including Sweden, Finland, Norway and Denmark, as well as those of Estonia and West Germany.

With regards to $\mathrm{H}_{2}$, there does not appear to be any clear association in Figure 4 between a country's/region's high levels of non-affiliation and greater differences in annual attendance (lower adjusted coefficients) between the unaffiliated and affiliated. Countries such as the Netherlands and Sweden have relatively high levels of non-affiliation (see Table 1), but weaker adjusted coefficients (see Figure 4). Others such as Italy and Croatia have relatively low levels of non-affiliation, but important differences between the unaffiliated and affiliated. This lack of an association is confirmed when a cross-level interaction term between non-affiliation and mean proportional size of the unaffiliated group in the country/region is added to the model and found not to be statistically significant. ${ }^{12}$

Figure 4: Adjusted Coefficient for Effect of Non-affiliation on Annual Religious Service Attendance, 40 Countries and Regions, 2008-2010, with CI (95\%)

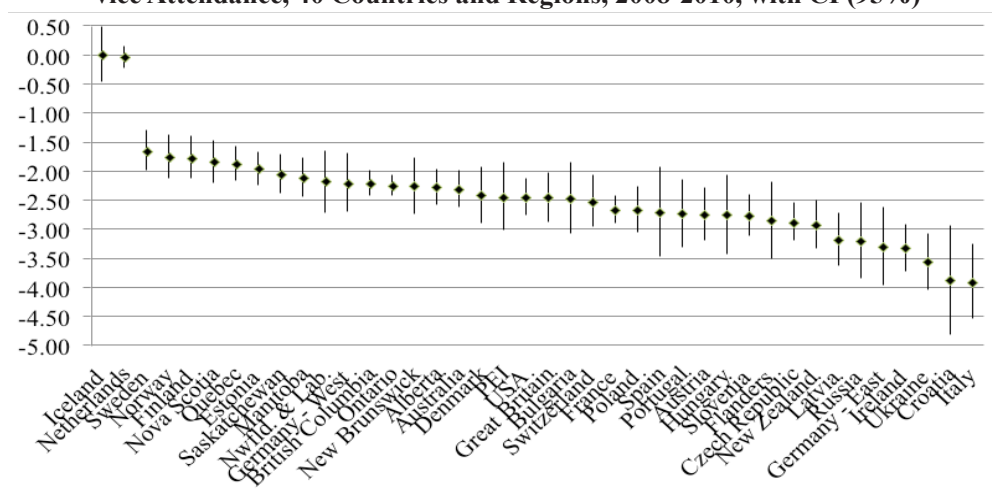

12. See Table A.8 in the online supplementary material. 
Nevertheless, when comparing countries/regions at either extreme in Figure 4 we are struck by the fact that traditionally Catholic countries generally have the largest differences, and the more Protestant countries generally have the smallest. Quebec appears to be the main exception to this rule, being traditionally Catholic yet having relatively smaller differences between the affiliated and unaffiliated when it comes to annual attendance. Quebec even shows a significantly smaller difference in this regard as compared with France, its French-speaking, traditionally Catholic and cultural sister. This indicates that, unlike what is often assumed, the contemporary religious dynamics at play in Quebec may not necessarily reflect those in France.

\section{Changes across Birth Cohorts in Levels of Personal Religiosity among the Unaffiliated}

Even with these Canadian and cross-national comparisons in hand, the question still remains: how have levels of personal religiosity among the unaffiliated in Canada changed across birth cohorts? Are these levels lower among younger generations, supporting the stages of decline hypothesis $\left(\mathrm{H}_{3}\right)$ ? Figure 5 contains the proportions of unaffiliated for each age group in each of the five Canadian regions. Figure 6 in turn contains the predicted means of the personal religiosity scale for the unaffiliated by region and by age group (five-year intervals). It is important to note here that variation across age groups, where it exists, is not only capturing potential age effects, meaning changes occurring within one lifetime as an individual ages and experiences life events, but also potential cohort effects, meaning intergenerational differences due to cohorts being born and raised in a different social environment than those before and after them.

Since religious individualization theory proposes only personal religiosity indicators will remain high among the unaffiliated, we focus here on the changes in levels of personal religiosity between age groups, rather than in levels of overall religiosity. However, trends are similar for both scales. ${ }^{13}$ We can see from the results in Figure 6 that trends are somewhat similar across the five Canadian regions. In Atlantic Canada, levels of personal religiosity are significantly lower among the unaffiliated in their teens and twenties, compared with those in their late fifties. A similar decline in levels of personal religiosity among younger unaffiliated respondents is also present in Quebec, Ontario and the Prairies. In British Columbia, there is a hint of a similar decline, especially between unaffiliated respondents aged 20-24 years and those aged 50-74 years, but it is not as pronounced as in the other Canadian regions.

13. See Figure A.3 in the online supplementary material for the predicted means of the overall religiosity scale among the unaffiliated of each age group in each Canadian region. 
Figure 5: Proportion of Individuals Declaring No Religion, by Canadian Region and Age Group (five-year groups: 15-19 years to 80 years or more) 2008-2010 Weighted
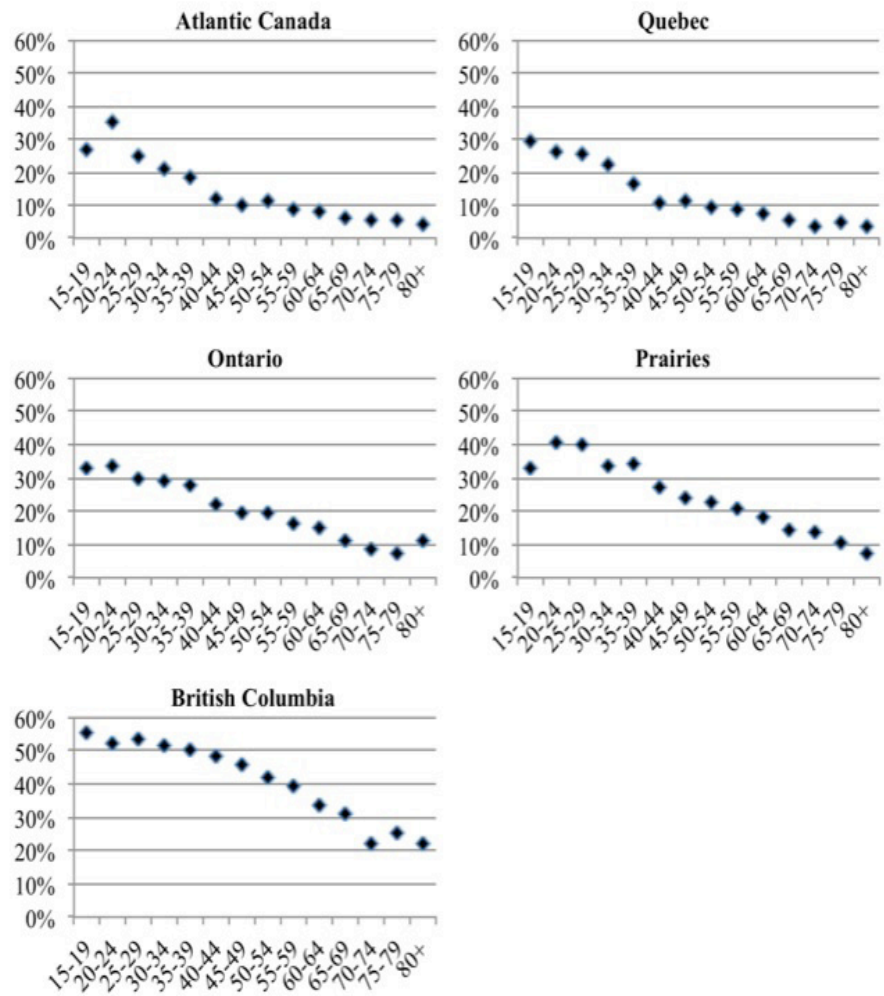
Figure 6: Predicted Mean Score of Personal Religiosity among the Unaffiliated, by Canadian Region and Age Group (five-year groups: 15-19 years to 80 years or more), 2008-2010, with CI $(95 \%)$
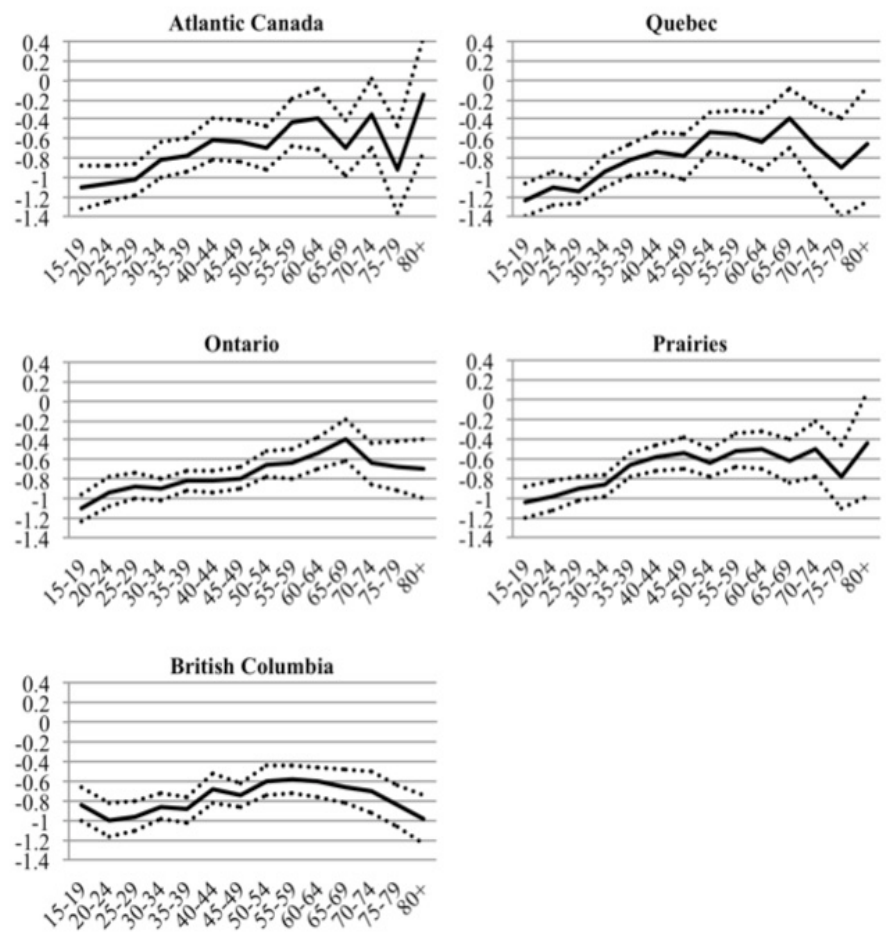

This decline in levels of personal religiosity among younger age groups could be due to an age effect: when individuals get older, they become more religious. It could also be due to a cohort effect: as rates of non-affiliation have increased among younger cohorts, the mean levels of religiosity among this group have decreased. Although both effects could be at play simultaneously, existing research points to cohort effects having a larger impact when it comes to religious change in general, and especially non-affiliation (Baker and Smith 2009b; Bibby 2011; Hout and Fisher 2002; Voas and Crockett 2005). This being said, since we are using cross-sectional data we cannot confirm this. What we can say is these declines in mean personal religiosity among younger unaffiliated respondents do initially support $\mathrm{H} 3$ : as the unaffiliated population grows in younger age groups, religion generally becomes less present. Further 
studies will have to be done to see if these younger unaffiliated individuals keep these low levels of religiosity as they age.

\section{Discussion}

With the results seen in the previous sections, we can establish first of all that the religiously unaffiliated in Canada do not form one homogenous group devoid of all forms of religiosity. Yes, individuals declaring having no religion are generally less religious than their affiliated counterparts; yes, levels of monthly religious service attendance are extremely low among the unaffiliated; and yes, $63 \%$ of the unaffiliated in Canada fall within the lowest quartile when ranking the general population according to mean levels of overall religiosity. Yet, a fifth of the unaffiliated in Canada attend religious services annually, on top of potentially attending for rites of passage such as marriages, baptisms and funerals; over a seventh practice personal religiosity on their own at least once a week; a third consider their religious and/or spiritual beliefs as important in how they live their lives; and a fifth score above the population average when it comes to mean levels of overall religiosity in Canada.

Unaffiliated respondents in the province of Quebec have the lowest levels of religiosity in the country, a reflection of low levels of religiosity in the province as a whole. In this sense, Quebec seems to buck the overall trend of Catholic countries having higher levels of religiosity in the West (Aarts et al. 2010; Voas 2009), and larger differences between the unaffiliated and affiliated (see Figure 4). This Quebec exceptionalism may be born of a peculiar context in which prevails both a strong wariness towards the Church as an institution and its practices (inherited from the Quiet Revolution), and yet also a need to retain historical and cultural links to Catholicism as a group marker distinguishing the Francophone majority in Quebec from an English-speaking and perceived Protestant majority elsewhere in North America (Lemieux 1990; Meunier and Wilkins-Laflamme 2011). From the results seen in Table 1 and Figure 4, this current religious paradox between institutional dislike and cultural defense appears even to make Quebec distinct from its cultural homeland of France, at least regarding annual attendance among the unaffiliated.

We also saw that the stages of decline framework is not particularly helpful in understanding cross-provincial and cross-national differences in levels of religiosity among the unaffiliated, nor in understanding the varying differences in these levels between the unaffiliated and affiliated. The results in the first two sections do not support $\mathrm{H}_{1}$ or $\mathrm{H}_{2}$. The unaffili- 
ated are not necessarily less religious in areas with more advanced secularization (larger unaffiliated groups), nor are these levels of religiosity more dissimilar between the unaffiliated and affiliated in such areas. Yet, there is cross-provincial and cross-national variation. This indicates that the individualization framework is also not the best framework to understand these results with, since it would predict few differences in levels of personal religiosity between the unaffiliated of different areas (individuals having basic spiritual needs which must be met, even if by their own means rather than by an institution's). Other contextual factors appear to be at play. The results in Figure 4 indicate that it may be best to turn towards a nuanced secularization theory such as David Martin's $(1978 ; 2005)$. Martin emphasizes the importance of an area's traditional religious structure (Protestant, Catholic, Orthodox or mixed) in the process of contemporary religious decline and transformation. However, when it came to differences between birth cohorts in the third section of results, we saw more support for the stages of decline framework $\left(\mathrm{H}_{3}\right)$. Levels of personal religiosity have generally declined among unaffiliated Post-Boomer birth cohorts in all five Canadian regions. Although not simultaneous, both institutional and personal religiosity indicators are seeing decline among younger generations characterized more and more by minimal, if any, religious socialization as well as secular social environments.

These findings do have their limits. The present study was restricted to a small number of specific religiosity indicators for a recent but short period of time. As a result, more religiosity indicators (such as adherence to specific beliefs, level of religious socialization, etc.) over a longer period could yield a more complete picture of religiosity among the unaffiliated in Canada, and how this religiosity has changed over the years. Additionally, panel data with a sufficiently large sample size could better grasp if being unaffiliated is a lifelong event, as well as the effect of various life events on religiosity levels among the unaffiliated. Qualitative research, such as analyses of humanist movements' discourse and writings or in-depth interviews with individuals declaring having no religion, would also contribute to a much better understanding of an unaffiliated individual's religious and spiritual experiences, or lack thereof, and how they relate to religion in general in Canadian society.

The present article also did not focus on the evolution of levels of religiosity among the rest of the Canadian population (the affiliated). Other recent research has shown that, although non-affiliation has increased proportionally across the country in recent decades, actively religious groups with relatively high levels of religiosity have stabilized proportionally in Western Canada over the same period (Wilkins-Laflamme 
2014). In these areas, decline is coming more from the middle ground of nominal affiliation (affiliation without regular religious service attendance). Therefore, Canada may not necessarily be headed towards becoming a completely secular society devoid of all forms of religion. Rather, the landscape in the coming years may be a religiously polarized one where an unaffiliated majority more and more cut off from all forms of religiosity stands opposite smaller committed religious groups able to reproduce themselves demographically due to higher fertility rates and gains from non-Western immigration (Kaufmann 2010; Kaufmann, Goujon, and Skirbekk 2012; Norris and Inglehart 2011). This growing divide between the religious and the secular is something social scientists may have to contend with in their studies on other social phenomena which religiosity is known to affect, such as political behaviour, volunteering, family formation and educational choices. Policy makers should also be aware of this growing divide as a source of potential social conflict.

\section{REFERENCES}

Aarts, Olav, Ariana Need, Manfred Te Grotenhuis, and Nan Dirk De Graaf. 2008. Does Belonging Accompany Believing? Correlations and Trends in Western Europe and North America Between 1981 and 2000. Review of Religious Research 50 (1):16-34.

2010. Does Duration of Deregulated Religious Markets Affect Church Attendance? Evidence from 26 Religious Markets in Europe and North America Between 1981 and 2006. Journal for the Scientific Study of Religion 49 (4):657-672.

Altemeyer, Bob. 2009. Atheism and Secularity in North America. In Atheism and Secularity [volume 2], edited by Phil Zuckerman, 1-21. Santa Barbara, CA: ABC-CLIO.

Ang, Adrian and John R. Petrocik. 2012. Religion, Religiosity, and the Moral Divide in Canadian Politics. Politics and Religion 5 (1):103-132.

Baker, Joseph O. Brian. 2012. Perceptions of Science and American Secularism. Sociological Perspectives 55 (1):167-188.

Baker, Joseph O. Brian and Buster G. Smith. 2009a. None Too Simple: Examining Issues of Religious Nonbelief and Nonbelonging in the United States. Journal for the Scientific Study of Religion 48 (4):719-733.

2009b. The Nones: Social Characteristics of the Religiously Unaffiliated. Social Forces 87 (3):1251-1263.

Beyer, Peter 2006. Transformations et pluralisme : les données des recensements de 1981 à 2001. In La religion dans la sphère publique, edited by S. Lefebvre, 12-40. Montréal: Presses de l’Université de Montréal. 
Bibby, Reginald W. 2002. Restless Gods: The Renaissance of Religion in Canada. Toronto: Stoddart Publishing.

2011. Beyond The Gods \& Back: Religion's Demise and Rise and Why It Matters. Lethbridge AB: Project Canada Books.

Bowen, Kurt. 2004. Christians in a Secular World: The Canadian Experience. Montréal: McGill-Queen's University Press.

Bramadat, Paul. and David. Seljak (eds.). 2005. Religion and Ethnicity in Canada. Toronto: Pearson Longman.

Bruce, Steve. 2011. Secularization: In Defence of an Unfashionable Theory. Oxford: Oxford University Press.

Campiche, Roland. J. 2010. La Religion visible. Lausanne: Presses Polytechniques et Universitaires Romandes.

Cimino, Richard and Christopher Smith. 2011. The New Atheism and the Formation of the Imagined Secularist Community. Journal of Media and Religion 10 (1):24-38.

Davie, Grace. 2000. Religion in Modern Europe. A Memory Mutates. Oxford: Oxford University Press.

Demerath III, N. Jay. 2000. The Rise of 'Cultural Religion' in European Christianity: Learning from Poland, Northern Ireland, and Sweden. Social Compass 47 (1):127-139.

Dobbelaere, Karel. 2002. Secularization: An Analysis at Three Levels. Vol. 1. New York: Peter Lang Publishing.

Eagle, David. 2011. Changing Patterns of Attendance at Religious Services in Canada, 1986-2008. Journal for the Scientific Study of Religion 50 (1):187-200.

Eggebeen, David and Jeffrey Dew. 2009. The Role of Religion in Adolescence for Family Formation in Young Adulthood. Journal of Marriage and Family 71 (1):108-121.

Evans, Geoffrey and Nan Dirk de Graaf (eds.). 2013. Political Choice Matters: Explaining the Strength of Class and Religious Cleavages in Cross-National Perspective. Oxford: Oxford University Press.

Hayes, Bernadette C. 2000. Religious Independents within Western Industrialized Nations: A Socio-Demographic Profile. Sociology of Religion 61 (2):191-207.

Hervieu-Léger, Danièle. 2003. Catholicisme, la fin d'un monde. Paris: Bayard.

Hout, Michael and Claude S. Fisher. 2002. Why More Americans Have No Religious Preference: Politics and Generations. American Sociological Review 67 (1):165-190.

ISSP Research Group. 2012. International Social Survey Programme (ISSP): 2008-2010. GESIS: Cologne Germany ZA4850 [distributor]. 
Kaufmann, Eric. 2010. Shall the Religious Inherit the Earth?: Demography and Politics in the Twenty-First Century. London: Profile Books.

Kaufmann, Eric, Anne Goujon, and Vegard Skirbekk. 2012. The End of Secularization in Europe? A Socio-Demographic Perspective. Sociology of Religion 73(1):69-91.

Koenig, Harold, Dana King, and Verna B. Carson. 2012. Handbook of Religion and Health. Oxford: Oxford University Press.

Lemieux, Raymond. 1990. Le Catholicisme québécois : une question de culture. Sociologie et sociétés 22 (2):145-164.

Lim, Chaeyoon and Carol Ann MacGregor. 2012. Religion and Volunteering in Context: Disentangling the Contextual Effects of Religion on Voluntary Behavior. American Sociological Review 20 (10):1-33.

Lim, Chaeyoon, Carol Ann MacGregor, and Robert D. Putnam. 2010. Secular and Liminal: Discovering Heterogeneity Among Religious Nones. Journal for the Scientific Study of Religion 49 (4):596-618.

Loury, Linda D. 2004. Does Church Attendance Really Increase Schooling? Journal for the Scientific Study of Religion 43 (1):119-127.

Martin, David. 1978. A General Theory of Secularization. Oxford: Basil Blackwell.

2005. On Secularization. Towards a Revised General Theory. Burlington: Ashgate.

Mayrl, Damon and Freeden Oeur. 2009. Religion and Higher Education: Current Knowledge and Directions for Future Research. Journal for the Scientific Study of Religion 48 (2):260-275.

Meunier, E.-Martin and Sarah Wilkins-Laflamme. 2011. Sécularisation, catholicisme et transformation du régime de religiosité au Québec. Étude comparative avec le catholicisme au Canada (1968-2007). Recherches Sociographiques 52 (3):683-729.

Milot, Micheline. 2002. Laïcité dans le Nouveau Monde. Le cas du Québec. Coll. Bibliothèque des Hautes Études / Sorbonne. Turnhout: Brepols Publishers.

Mitchell, Claire. 2004. Is Northern Ireland Abnormal? : An Extension of the Sociological Debate on Religion in Modern Britain. Sociology 38 (1):237254.

Norris, Pippa and Ronald Inglehart. 2011. Sacred and Secular: Religion and Politics Worldwide. Cambridge: Cambridge University Press.

Stark, Rodney. and Roger Finke. 2000. Acts of Faith: Explaining the Human Side of Religion. Los Angeles: University of California Press.

Statistics Canada. 2012. General Social Survey [Canada]: Cycles 1-24 (19852010). Public use microdata file. 
Storm, Igrid. 2009. Halfway to Heaven: Four Types of Fuzzy Fidelity in Europe. Journal for the Scientific Study of Religion 48 (4):702-718.

Village, Andrew, Emyr Williams, and Leslie J. Francis. 2010. Living in Sin? Religion and Cohabitation in Britain 1985-2005. Marriage \& Family Review 46:468-479.

Voas, David. 2009. The Rise and Fall of Fuzzy Fidelity in Europe. European Sociological Review 25 (2):155-168.

Voas, David. and Alasdair. Crockett. 2005. Religion in Britain: Neither Believing nor Belonging. Sociology 39 (1):11-28.

Wilkins-Laflamme, Sarah. 2014. Towards Religious Polarization? Time Effects on Religious Commitment in US, UK and Canadian Regions. Sociology of Religion 75 (2):284-308.

Zuckerman, Phil (ed.). 2009. Atheism and Secularity [2 volumes]. Santa Barbara, CA: ABC-CLIO.

Sarah Wilkins-Laflamme is an assistant professor of sociology at the University of Waterloo. She completed her DPhil (PhD equivalent) in sociology in 2015 at the University of Oxford (UK). Her research interests include sociology of religion, quantitative methods, political sociology as well as ethnic, linguistic and cultural minorities.

sarah.wilkins-laflamme@uwaterloo.ca 